American Journal of Applied Sciences 1 (3): 193-201, 2004

ISSN 1546-9239

(C) Science Publications, 2004

\title{
House Price Prediction: Hedonic Price Model vs. Artificial Neural Network
}

\author{
${ }^{1}$ Visit Limsombunchai, ${ }^{2}$ Christopher Gan and ${ }^{2,3}$ Minsoo Lee \\ ${ }^{1}$ P.O Box 84, Lincoln University, Canterbury 8150, New Zealand \\ ${ }^{2}$ Commerce Division, Lincoln University, New Zealand \\ ${ }^{3}$ Department of Economics, American University of Sharjah, UAE
}

\begin{abstract}
The objective of this study is to empirically compare the predictive power of the hedonic model with an artificial neural network model for house price prediction. A sample of 200 houses in Christchurch, New Zealand is randomly selected from the Harcourt website. Factors including house size, house age, house type, number of bedrooms, number of bathrooms, number of garages, amenities around the house and geographical location are considered. Empirical results support the potential of artificial neural network on house price prediction, although previous studies have commented on its black box nature and achieved different conclusions.
\end{abstract}

Key words: Hedonic Model, Artificial Neural Network, House Price

\section{INTRODUCTION}

An accurate prediction on the house price is important to prospective homeowners, developers, investors, appraisers, tax assessors and other real estate market participants, such as, mortgage lenders and insurers $^{[1]}$. Traditional house price prediction is based on cost and sale price comparison lacking of an accepted standard and a certification process. Therefore, the availability of a house price prediction model helps fill up an important information gap and improve the efficiency of the real estate market ${ }^{[2]}$.

In New Zealand, most people know the benefit of owning a house, because buying a house is considered the most utilized and profitable investment. New Zealand has one of the highest ratios of people owning their houses in the western world with over $70 \%$ of its citizens living in their own houses. As the housing market in New Zealand is thriving, house price becomes a crucial factor for house seekers.

Over the last two decades there has been a proliferation of empirical studies analyzing residential property values. Each succeeding research has generally improved the predictive power of the models by emphasizing the attributes of property value such as housing site, housing quality, geographical location and the environment. More recent studies have focused on location externalities, transaction costs and factors affecting the future expected cost in home ownership ${ }^{[3]}$.

The hedonic pricing models have been commonly used to estimate house prices and property values. Most of the models include housing attributes such as location, neighborhood and house size. However, there are a limited number of studies in this area using an artificial neural network technique. This study uses the hedonic method and artificial neural network to empirically determine the house prices in Christchurch,
New Zealand. Secondary data from 200 houses in Christchurch is used in a hedonic price framework and artificial neural network to empirically compare the predictive power of both techniques and to suggest an appropriate technique for the house price prediction.

Hedonic price theory: Hedonic price theory assumes that a commodity such as a house can be viewed as an aggregation of individual components or attributes ${ }^{[4]}$. Consumers are assumed to purchase goods embodying bundles of attributes that maximize their underlying utility functions ${ }^{[5]}$. Describes the process in which prices reveal quality variations as relying on producers who "tailor their goods to embody final characteristics described by customers and receive returns for serving economic functions as mediaries". Hedonic price theory originates from ${ }^{[6]}$ proposal that goods are inputs in the activity of consumption, with an end product of a set of characteristics.

Bundles of characteristics rather than bundles of goods are ranked according to their utility bearing abilities.

Attributes (for example, characteristics of a house such as number of bedrooms, number of bathrooms, number of fireplaces, parking facilities, living area and lot size) are implicitly embodied in goods and their observed market prices. The amount or presence of attributes associated with the commodities defines a set of implicit or "hedonic" prices ${ }^{[5]}$. The marginal implicit values of the attributes are obtained by differentiating the hedonic price function with respect to each attribute $^{[7]}$. The advantage of the hedonic methods is that they control for the characteristics of properties, thus allowing the analyst to distinguish the impact of changing sample composition from actual property appreciation $^{[8]}$. 
Hedonic price theory has been applied to the valuation of agricultural commodities ${ }^{[9,10,11]}$, residential amenities $^{[7,12,13,14]}$ and wildlife related recreation resources $^{[15,16,17,18]}$. Other applications involve the estimation of the benefits of environmental improvements ${ }^{[7,12,19,20]}$.

While the hedonic technique is an acceptable method for accommodating attribute differences in a house price determination model, it is generally unrealistic to deal with the housing market in any geographical area as a single unit. Therefore, it seems more reasonable to introduce geographical information or location factor into a model that allows shifts in the house price level ${ }^{[21]}$. employ The hedonic pricing model to examine the relationship between location and property value, in Portland, Oregon and the authors found that there was a significant relationship between location and property value ${ }^{[22]}$.

Examine whether it is more appropriate to use aggregate or disaggregate data in forecasting house price using the hedonic analysis. It is found that the hedonic price coefficients of some attributes are not stable between locations, property types and age. However, it is argued that this can be effectively modelled with an aggregate method. The hedonic price model has also been used to estimate individual external effects (e.g. environmental attributes) on house prices. For example, there are a number of studies that have applied the hedonic price model in quantifying the effects of noise $\mathrm{e}^{[23,24,25]}$ and air pollution on house prices $^{[26,27]}$.

Even though the hedonic price model has been widely recognized, issues such as model specification procedures, multicollinearity, independent variable interactions, heteroscedasticity, non-linearity and outlier data points can seriously hinder the performance of the hedonic price model in real estate valuations. The artificial neural network model has been offered as a possible solution to many of these problems, especially when the data patterns show non-linearity ${ }^{[28,29,30]}$.

Using a large sample of data from the apartment sector in Singapore, found that a neural network model performs better than a multiple regression model for estimating value. The authors concluded that the neural network can learn valuation patterns for "true" open market sales in the presence of some "noise" as a way of establishing a robust estimator. Similar results can be found in ${ }^{[31,32]}$ studies $^{[33]}$.

On the other hand, take on a contrary position and cast some doubt upon the role of neural networks compared to the traditional regression models. The authors argued that even when the same data is used, results from models prepared by different neural network software package could be inconsistent and did not always outperform regression models ${ }^{[28]}$. Also reached the similar conclusions. Their study documented very similar performance between the hedonic model and the neural network models.

Artificial neural network theory: Neural network is an artificial intelligence model originally designed to replicate the human brain's learning process. The model consists of three main layers: input data layer (example the property attributes), hidden layer(s) (commonly referred as "black box") and the output layer (estimated house price). The neural network is an interconnected network of artificial neurons with a rule to adjust the strength or weight of the connections between the units in response to externally supplied data (Fig. 1) ${ }^{[34]}$.

Each artificial neuron (or computational unit) has a set of input connections that receive signals from other computational units and a bias adjustment, a set of weights for input connection and bias adjustment and transfer function that transforms the sum of the weighted inputs and bias to decide the value of the output from the computational unit (Fig. 2). The output of the computation unit (node $\mathrm{j}$ ) is the result of applying a transfer function $\varphi$ to the summation of all signals from each connection $\left(\mathrm{A}_{\mathrm{i}}\right)$ times the value of the connection weight between node $\mathrm{j}$ and connection $\mathrm{I}$ $\left(\mathrm{W}_{\mathrm{ji}}\right)$ (refer to equations 1 and 2 ):

$$
\begin{aligned}
& \operatorname{Sum}_{j}=\sum_{j}\left(W_{j i} A_{i}\right) \\
& O_{j}=\varphi\left(\operatorname{Sum}_{j}\right)
\end{aligned}
$$

where, $\mathrm{O}_{\mathrm{j}}$ is output for node $\mathrm{j}$ and $\varphi$ is transfer function which can take many different forms: linear functions, linear threshold functions, step linear functions, sigmoid function or Gaussian functions ${ }^{[35]}$.

Hedonic price model: The hedonic model involves regressing observed asking-prices for the house against those attributes of a house hypothesized to be determinants of the asking-price. Attributes hypothesized to contribute to the price of a house include land size (in square meters), his age (in years), number of bedrooms, number of bathrooms, number of toilets and number of garages, binary variables representing the type of house (with garden, or without garden) and amenities around the residential areas (such public facilities).

In addition, the geographical location of the house also plays an important factor in influencing the house price. In this study, the Christchurch area is divided into six different geographical locations. They are Inner Christchurch, North Christchurch, South Christchurch, East Christchurch, West Christchurch and Northwest Christchurch. The location dummy variables equal to 1 if a particular property is situated in the identified location, 0 otherwise. 


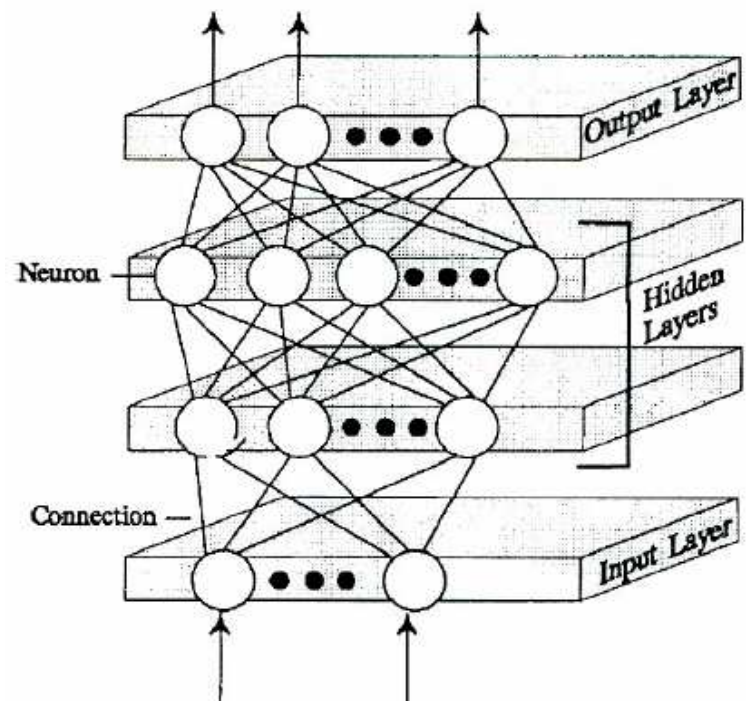

Fig. 1: Feed-forward neural network structure with two hidden layers

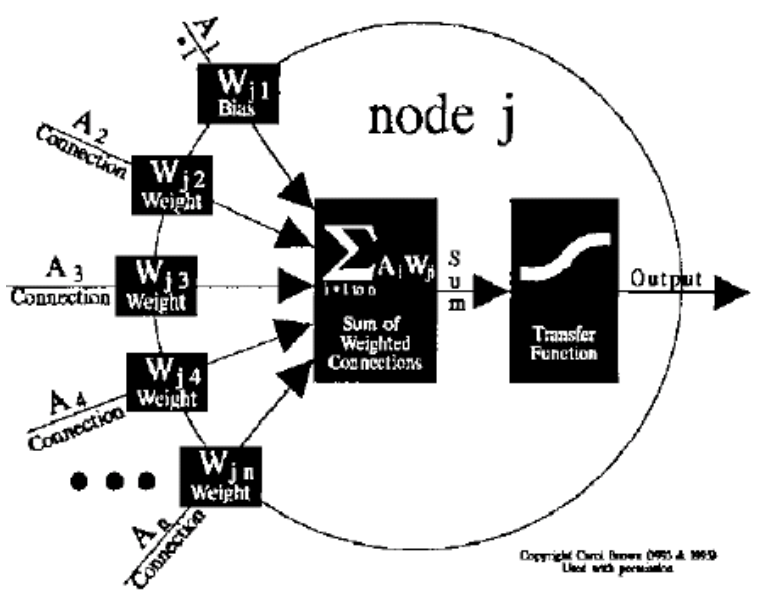

Fig. 2: Structure of a computational unit (node j)

Implicitly, the model for the hedonic price function is specified as:

$\begin{aligned} \text { PRICE }= & \mathrm{f}(\text { LAND, AGE, TYPE, BEDROOMS, } \\ & \text { BATHROOMS, GARAGES, } \\ & \text { AMENITIES, INNER CHRISTCHURCH, } \\ & \text { NORTH CHRISTCHURCH, SOUTH } \\ & \text { CHRISTCHURCH, EAST } \\ & \text { CHRISTCHURCH, WEST } \\ & \text { CHRISTCHURCH, NORTHWEST } \\ & \text { CHRISTCHURCH, } \varepsilon)\end{aligned}$

Variables in the model are defined as:

$\begin{array}{ll}\text { PRICE } & =\text { Price of house in Christchurch in } \\ \text { NZD } & =\text { Land size (in square meters) }\end{array}$

AGE (-) = Age of the house (in years)

TYPE (+) = Type of the house; 1 if the house has a garden, 0 otherwise

BEDROOMS $(+)=$ Number of bedrooms

BATHROOMS $(+)=$ Number of bathrooms

GARAGES $(+) \quad=$ Number of garages

AMENITIES (+) = Amenities around the house; 1 if the house is close to two or more public facilities (i.e., Bus stop, school, public park and so on), 0 otherwise $\_=$Error term

A priori hypothesis are indicated by (+) and (-) in the above specification. Based on previous literature, it is hypothesized that most of the variables have a positive relationship with the house price, except age of the house. For example, a house with a garden is more expensive than a house without a garden. A small house should cheaper than a large house. A house that has multiple bedrooms, bathrooms, garages and close to public amenities (such as public parks, public libraries) is expected to command a higher price than a house that has the least number of bedrooms, bathrooms, toilets, garages and no public amenities nearby. Conversely, the age of a house would have a negative relationship with house price since an old house command a lower price compared to a newly built house.

Artificial neural network model: The use of the neural network model is similar to the process utilized in building the hedonic price model. However, the neural network must first be trained from a set of data. For a particular input, an output (estimated house price) is produced from the model. Then, the model compares the model output to the actual output (actual house price). The accuracy of this value is determined by the total mean square error and then back propagation is used in an attempt to reduce prediction errors, which is done through the adjusting of the connection weights. The performance of the network can be influenced by the number of hidden layers and the number of nodes that are included in each hidden layer. Unfortunately, there exists a little theory to support the process for the determination of the optimal number of hidden layers and nodes and also the optimal internal error threshold $^{[28]}$. Therefore, a trial-and-error process is applied to find the optimal artificial neural network model. A feed-forward/back-propagation neural network software package, NeuroShell, was used to construct the artificial neural network model.

There are no assumptions about functional form, or about the distributions of the variables and errors of the model, the neural network model is more flexible than 
the standard statistical technique ${ }^{[36]}$. It allows for nonlinear relationship and complex classificatory equations. The user does not need to specify as much detail about the functional form before estimating the classification equations but, instead, it lets the data determine the appropriate functional form.

In accordance to standard analytical practice, the sample size was divided on a random basis into 2 sets, namely the "training set" and the "production set" (as known in neural network literature), or the "estimation set" and the "forecasting set" (as know in regression analysis literature). The training set and the production set contain 80 and $20 \%$ of the total sample, respectively. To evaluate the forecasting accuracy of both models, the data in forecasting set (or production set) are used and an out-of-sample forecasting is operated, subsequently, the $\mathrm{R}^{2}$ and the Root Mean Square Error (RMSE) were calculated and compared (equations 4 and 5). The model with a higher $\mathrm{R}^{2}$ and lower RMSE was considered to be a relatively superior model:

$$
R^{2}=1-\frac{\sum_{i=1}^{n}\left(P_{i}-\hat{P}_{i}\right)^{2}}{\sum_{i=1}^{n}\left(P_{i}-\bar{P}\right)^{2}}
$$

$$
\text { RMSE }=\sqrt{\frac{1}{n} \sum_{i=1}^{n}\left(P_{i}-\hat{P}_{i}\right)^{2}}
$$

where $P_{i}$ is actual house price, $\hat{P}_{i}$ is estimated house price and $n$ is the number of observations.

Data and procedures: A sample of 200 housing information in the Christchurch area is randomly selected from the largest real estate agent, Harcourt. The data set is retrieved from Harcourt's website (www.bluebook.co.nz) in May 2003.

Since most business offices, restaurants and shops are located in the inner city center, the proportion of residential houses is quite small. Fifteen housing data are collected from the inner city, 25 housing information is from North Christchurch and 40 housing information for the remaining four identified locations. There are 200 observations utilized in this study.

Economic theory offers little guidance with respect to the choice of functional form for the hedonic model as the hedonic price function represents an equilibrium relationship derived from individuals' preferences and suppliers' cost functions ${ }^{[37]}$. While earlier hedonic studies used linear specifications, recent investigations aimed at identifying more appropriate functional specifications have indicated the superiority of flexible forms ${ }^{[38,14]}$. Coefficients resulting from linear specifications identify the relative contribution of their respective attributes to the price of the product. Linear specifications, however, imply constant marginal willingness-to-pay for all households consuming the $\operatorname{good}^{[19]}$. This does not allow for the identification of the demand schedule for the attribute in question and also ignores the possibility that demand for the attribute may be a function of its level as well as the level of other attributes. In the case of nonlinear specifications, the first derivative of the hedonic price function with respect to the specified attribute yields the implicit marginal price of the attribute ${ }^{[7]}$.

As economic theory provides no clear guidance regarding the choice of functional form to be used in hedonic regression, this study employed the semi-log model, which assumes constant percentage partial effects, because price is a very sensitive and volatile component ${ }^{[39]}$. Furthermore, some variables, such as age and garages contained some zero values. Therefore, the log-linear model may not be an appropriate functional form in this study, since it cannot take into the account of the newly built house and a house without a garage. However, both linear models, which implies constant partial effect and loglinear model, which allows for nonlinear price impacts, are also estimated. The results of both models, however, are not presented here because of relatively low $\mathrm{R}^{2}$ (on the linear model), incorrect sings and statistically insignificant on many coefficients (on both models).

\section{RESULTS AND DISCUSSION}

The estimated coefficients of equation 3 are shown in Model 1 (Table 1). The Weighted Least Square (WLS) technique and the ${ }^{[40]}$ adjustment for estimating a heteroscedasticity consistent covariance matrix are applied to equation 3 instead of the ordinary least square technique because of heteroscedasticity problem. Using the rule of thumb, the correlation coefficient in excess of 0.80 is considered very high and may cause a serious multicollinearity problem ${ }^{[41]}$. Therefore, the number of toilets was dropped from equation 3 to avoid multicollinearity problem since the correlation coefficient between the number of Toilets (TO) and the number of Bathrooms (BA) is 0.85 (Table 2). On the other hand, the correlation coefficient between house price $(\mathrm{P})$ and land size $(\mathrm{L})$ is 0.09 . The low correlation coefficient implies a low degree of linear association. However, it does not mean that the two variables are independent as they may have nonlinear relationship. 
American J. Appl. Sci., 1 (3), 193-201, 2004

Table 1: Correlation coefficient matrix

\begin{tabular}{lllllll}
\hline & $\mathrm{P}$ & $\mathrm{L}$ & $\mathrm{A}$ & $\mathrm{BD}$ & $\mathrm{BA}$ & $\mathrm{TO}$ \\
\hline $\mathrm{P}$ & 1.00 & & & & & \\
$\mathrm{~L}$ & 0.09 & 1.00 & 1.00 & & & \\
$\mathrm{~A}$ & -0.19 & 0.30 & -0.12 & 1.00 & & \\
$\mathrm{BD}$ & 0.18 & 0.50 & -0.33 & 0.61 & 1.00 & \\
$\mathrm{BA}$ & 0.35 & 0.22 & -0.35 & 0.58 & 0.85 & 1.00 \\
TO & 0.47 & 0.20 & -0.32 & 0.52 & 0.52 & 0.53 \\
G & 0.33 & 0.35 & & & & 1.00 \\
\hline
\end{tabular}

Table 2: Hedonic price models

\begin{tabular}{|c|c|c|c|}
\hline & & \multicolumn{2}{|c|}{ Coefficient } \\
\hline \multicolumn{2}{|l|}{ Variable1/t } & \multicolumn{2}{|c|}{ Model $1^{2 /}$} \\
\hline \multicolumn{2}{|l|}{$\mathrm{C}$} & \multicolumn{2}{|c|}{$11.1763 * *$} \\
\hline \multicolumn{2}{|l|}{ LAND (L) } & \multicolumn{2}{|l|}{0.0001} \\
\hline \multicolumn{2}{|l|}{ AGE (A) } & \multicolumn{2}{|c|}{$-0.0028^{*}$} \\
\hline \multicolumn{2}{|l|}{ TYPE (TY) } & \multicolumn{2}{|c|}{$0.3599^{*}$} \\
\hline \multicolumn{2}{|l|}{ BEDROOMS (BD) } & \multicolumn{2}{|c|}{0.0788} \\
\hline \multicolumn{2}{|l|}{ BATHROOMS (BA) } & \multicolumn{2}{|c|}{$0.2411 * *$} \\
\hline \multicolumn{2}{|l|}{ GARAGES (G) } & \multicolumn{2}{|c|}{$0.1826^{*}$} \\
\hline \multicolumn{2}{|l|}{ AMENITIES (AM) } & \multicolumn{2}{|c|}{0.0366} \\
\hline \multicolumn{2}{|l|}{ North Christchurch (NC) } & \multicolumn{2}{|c|}{$-0.1955^{*}$} \\
\hline \multicolumn{2}{|l|}{ South Christchurch (SC) } & \multicolumn{2}{|c|}{$0.2759 * *$} \\
\hline \multicolumn{2}{|l|}{ East Christchurch (EC) } & \multicolumn{2}{|c|}{$-0.4521 * *$} \\
\hline \multicolumn{2}{|l|}{ West Christchurch (WC) } & \multicolumn{2}{|c|}{$-0.2250 *$} \\
\hline \multirow{2}{*}{\multicolumn{2}{|c|}{ Northwest Christchurch (NWC) }} & \multicolumn{2}{|c|}{$1.9423 * *$} \\
\hline & & 0.7833 & \\
\hline Adj. $R^{2}$ & & 0.7657 & \\
\hline F-stat. & & 44.291 & \\
\hline White Heteroscedasticity Test & & $\begin{array}{l}7.1970 \\
\mathrm{~N}=16\end{array}$ & \\
\hline $\begin{array}{l}\text { Note: } 1 / \text { Dependent Variable is } \\
\text { represent } 10 \text { and } 5 \% \text { significant } \\
\text { observations are used for out of } \\
\text { Model } 2 \text { is a hedonic pricing mod }\end{array}$ & $\begin{array}{l}\log (\mathrm{P}) 2 / \\
\text { level, resp } \\
\text { ample for } \\
\text { el for hous }\end{array}$ & $\begin{array}{l}\text { S and Wl } \\
\text { vely } 3 / 16 \\
\text { ts (Fig. 4) } \\
\text { th garden }\end{array}$ & $\begin{array}{l}\text { adjustme } \\
\text { out of } 200 \\
\text { Model } 1 \text { is a } \\
\text { lodel } 3 \text { is a }\end{array}$ \\
\hline Table & 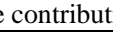 & tor & \\
\hline & Relative & ribution & \\
\hline Factor & Model 1 & Model 2 & Model 3 \\
\hline LAND (L) & 0.0879 & 0.1724 & 0.0608 \\
\hline $\operatorname{AGE}(\mathrm{A})$ & 0.2231 & 0.0936 & 0.1804 \\
\hline TYPE (TY) & 0.0766 & & \\
\hline BEDROOMS (BD) & 0.0649 & 0.0598 & 0.1749 \\
\hline BATHROOMS (BA) & 0.0621 & 0.1206 & 0.0517 \\
\hline GARAGES (G) & 0.1700 & 0.1615 & 0.1824 \\
\hline AMENITIES (AM) & 0.0675 & 0.0355 & 0.1160 \\
\hline North Christchurch (NC) & 0.0299 & 0.0747 & 0.0463 \\
\hline South Christchurch (SC) & 0.0306 & 0.0639 & na. \\
\hline East Christchurch (EC) & 0.0391 & 0.0453 & 0.0375 \\
\hline West Christchurch (WC) & 0.0493 & 0.0788 & 0.0319 \\
\hline Northwest Christchurch (NWC) & 0.0990 & 0.0940 & 0.1181 \\
\hline $\mathrm{R}^{2}$ & 0.9450 & 0.9942 & 0.9378 \\
\hline & $\mathrm{N}=160$ & $\mathrm{n}=124$ & $\mathrm{n}=36$ \\
\hline
\end{tabular}

Note: Ward network is utilized with learning rate $=0.1$, momentum $=$ 0.1 and initial weight $=0.3$ Model 1: house with and without garden Model 2: house with garden Model 3: house without a garden

The coefficients in Model 1 have the correct hypothesized signs and most of the coefficients are statistically significant. Thus, the high correlation coefficients between the number of bedrooms (BD) and the number of Bathrooms (BA) $(r=0.61)$, the number of garages $(\mathrm{G})$ and the number of Bedrooms (BD) $(r=$ $0.52)$ and the number of Garages $(\mathrm{G})$ and the number of Bathrooms (BA) $(r=0.52)$ are neither necessary nor sufficient to cause the multicollinearity problem, as

suggested by ${ }^{[42]}$. However, it should be noted that White heteroscedasticity test still indicate the presence of heteroscedasticity, even when the weighted least squares (WLS) and the White adjustment techniques are utilized.

The estimated results demonstrate that houses with more bedrooms and bathrooms are priced higher. A relatively new house is more expensive than an old house and a house with a garden is priced higher than one without a garden. Location variables play a significant role on house prices. For example, houses in the Northwest of Christchurch (such as Burnside, Fendalton, Ilam and Merivale) are priced higher since they have access to good public and private high schools in those areas due to the school-zone policy and the University of Canterbury. Furthermore, Fendalton has traditionally been known as an upper income area. On the contrary, properties in East of Christchurch (such as Linwood, Phillipstown, Aranui and Bexley) are priced lower than the rest of areas since it is relatively a poor neighborhood and most of the houses are relatively older than those in other areas.

In general, houses with gardens are usually located away from the city or shopping mall areas, while the houses without garden are located closer to the business district center, town and university. Thus, houses with gardens versus houses without gardens reflect different 
market segment and different pricing strategy. For example, the coefficient of house type (TY) in Model 1 shows the average price of a house with a garden is higher than a house without garden around 35\% in every location (Table 1). Therefore, it can be concluded that house prices can be determined differently according to its type.

The hedonic pricing models (Models 2 and 3) are segregated according to property type, that is, houses with gardens and houses without gardens respectively (Table 2). The $\mathrm{R}^{2}$ in both models is relatively high but the coefficients in both models, such as land size, garages and some geographical locations, are statistically not significant. Furthermore, the null hypothesis of the White heteroscedasticity test is rejected at 5 the percent level in both models. The results indicate that the segregation model improves the explanatory power of the model but cannot overcome the problem of heteroscedasticity. The insignificant of the variables may be caused by the reduction of the sample size since there are only 36 observations on the house without a garden model.

The back propagation training process is always regarded as a black box in the neural network model, thus the internal characteristics of a trained network are simply a set of numbers which prove to be difficult in relating back to the application in a meaningful fashion. For that reason, the learned output (weights or coefficients) cannot be interpreted or utilized as price adjustments.

The relative contribution factors of the best artificial neural networks (the relative importance of inputs) are shown in Table 3. All three networks employ the same variables for the input layer nodes that are used as the independent variables to create the hedonic price models. Ward networks (multiple hidden slabs with different activation functions), which use Gaussian, Tanh and Gaussian Complement ${ }^{[43]}$ as the activation functions for 3 hidden slabs and each slab contains 6 hidden nodes, are considered as the best networks in this study. Although neural networks with 1 and 2 hidden layers are examined and their results are slightly better than the hedonic price models, the results are not presented here because they do not outperform Ward networks.

The relative contribution factor in Table 3 shows that land size and number of garages are important factors that determine the house price for house with garden while amenities near the house area is the least important factor (Model 2). Generally, houses with gardens are located in the outskirt of the business district centers since they require large land sizes. Thus amenities around the house area may not be an important factor impact the house price. However, a larger land size means a higher price of the house.

For house without a garden, age of the house and the number of garages are factors that have a strong impact on the housing price (Model 3 in Table 3 ).
Table 4:Comparing the out-of-sample forecast evaluation results for hedonic price model and neural network model

\begin{tabular}{llll}
\hline Hedonic price model & Model 1 & Model 2 & Model 3 \\
\hline$-\mathrm{R}^{2}$ & 0.6192 & 0.7499 & 0.3807 \\
- RMSE & $876,215.63$ & $642,580.05$ & $1,435,810.81$ \\
Neural network model & & & \\
- $\mathrm{R}^{2}$ & 0.9000 & 0.8408 & 0.6907 \\
- RMSE & $449,111.46$ & $512,614.99$ & $1,014,721.92$ \\
& $\mathrm{~N}=40$ & $\mathrm{n}=31$ & $\mathrm{n}=9$ \\
\hline
\end{tabular}

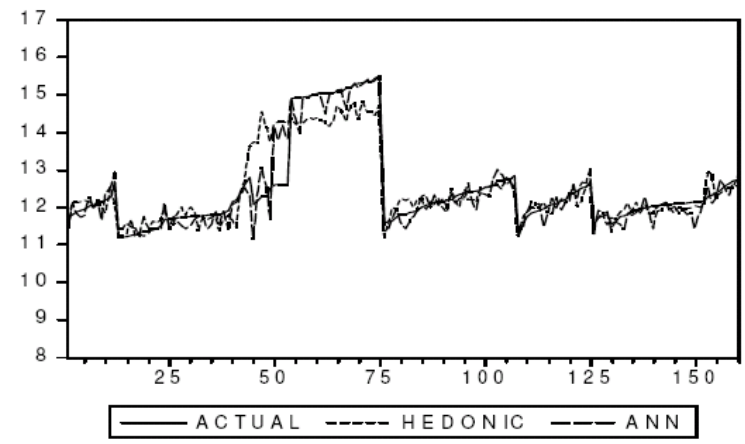

Fig. 3: Actual and Estimated house prices in log form (In sample forecast)

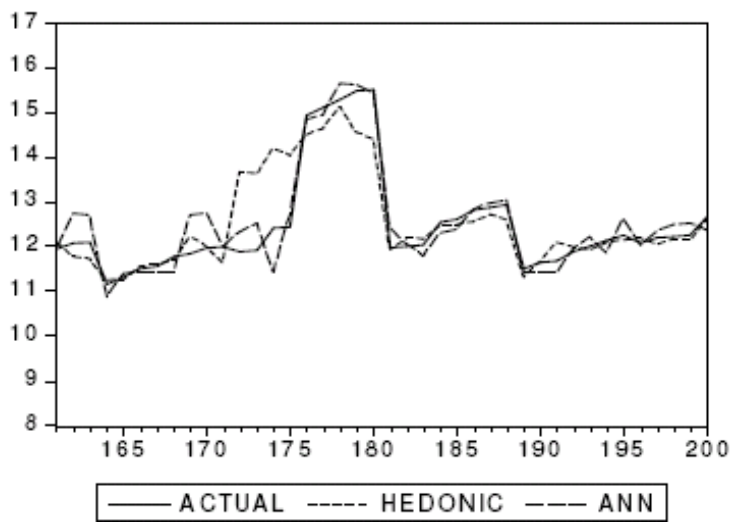

Fig. 4: Actual and estimated house prices in log form (Out-of-sample forecast)

Land size for the house without a garden is less important compared to house with garden. On the other hand, the age of the house, the number of bedrooms, the number of garages and amenities around the house areas do impact the house price for the house without garden when compared to the house with garden.

On the aggregate model (Model 1 in Table 3), the neural networks' relative contribution factor demonstrates that the age of the house and the number of garages, respectively, have contributed to the predictive power of model than the other variables. Geographical location such as Northwest of Christchurch has a relatively high impact on the house price compared to land size, house type, number of bedrooms, number of bathrooms and amenities around the house area. The result indicates that geographical location plays an important role in the house price determination. In addition, the relative contribution of 
the land size to the house price implied that land size and house price are dependent on each other and the relationship between them would be nonlinear, since its correlation coefficient is low and the coefficients of the land size are insignificant in all the models.

The $\mathrm{R}^{2}$ from neural network models are higher than the $\mathrm{R}^{2}$ from hedonic price models (Table 2 and 3 ). The results imply that the neural network model can estimate the house price more accurately than the hedonic price model in both aggregate and disaggregate models (Fig. 3). However, the results do not provide strong and conclusive evidence of superiority in term of prediction capability between both models, as shown by the sample results.

Table 4 shows the out-of-sample forecast evaluation results for hedonic price models and neural network models. Again, the $\mathrm{R}^{2}$ of neural network models is higher than the $\mathrm{R}^{2}$ of hedonic price models and the RMSE of neural network models are lower than hedonic price models. Therefore, it can be concluded that the neural network model is a relatively superior model for house price prediction (Fig. 4).

The results from Table 4 also suggest that the better model for house price prediction should be the aggregate neural network model rather than the disaggregate models, as it has the highest $\mathrm{R}^{2}$ and the lowest RMSE. Even though the neural network models for house with and without garden have relatively high $\mathrm{R}^{2}$ in the case of in sample forecast $(0.9942$ and 0.9378 , respectively), their performances are not good compared to the out-of-sample forecast, especially houses without gardens. The low number of observations may be one of the possible explanation for the poor performance of the model since the aggregate model has a higher number of observations than the disaggregate models.

\section{CONCLUSION}

This study empirically compares the predictive power of the hedonic price model with an artificial neural network model for house price prediction. Artificial neural network models and hedonic price models are tested for their predictive power using 200 house information in Christchurch, New Zealand.

The results from hedonic price models support the previous findings. Even if the $\mathrm{R}^{2}$ of hedonic price models is high (higher than 75\%) for in sample forecast, the hedonic price models do not outperform neural network models. Moreover, the hedonic price models show poorer results on out-of-sample forecast, especially when comparing with the neural network models. Thus, the empirical evidence presented in this study supports the potential of neural network on house price prediction, although previous literatures have commented upon its black box nature and reached different conclusions.

The presence of heteroscedasticity in the non-linear relationship between house attributes and house price is due to the lack of some environmental attributes and inadequate number of sample size could be the cause of the poor performance of the hedonic pricier models. Conversely, the artificial neural network model can overcome some of the problems related to the data patterns and the underlining assumption of the hedonic model. As a result, the model yields a better prediction result when compared with the hedonic model. Nevertheless, it should be noted that the optimal artificial neural network model is created by a trial-and error strategy. Without this strategy, the results may not indicate the superiority of the neural network model ${ }^{[28]}$.

There are, however, some limitations in this study. Firstly, the house price used is not the actual sale price but the estimated price due to the difficulty in obtaining the real data from the market. Secondly, this study considered only the current year's information on the houses. The time effect of the house price, which could potentially impact the estimated results was ignored (the same house should have different price in different years, assuming that age factor is constant). Finally, the house price could be affected by some other economic factors (such as exchange rate and interest rate) are not included in the estimation.

\section{REFERENCES}

1. Frew, J., and G. D. Jud, 2003. Estimating The Value of Apartment Buildings, The J. Real Estate Res., 25: 77 - 86.

2. Calhoun, C. A., 2003. Property Valuation Models and House Price Indexes for The Provinces of Thailand: 1992 - 2000. Housing Finance International, 17: $31-41$.

3. Norman, Miller G, 1982. Residential Property Hedonic Pricing Models. Research in Real Estate, pp. 31-56.

4. Griliches, Z., ed., 1971. Price Indexes and Quality Changes: Studies in New Methods of Measurement. Cambridge, Mass: Harvard U. Press.

5. Rosen, S., 1974. Hedonic Prices and Implicit Markets. Product Differentiation in Pure Competition, J. Political Econ., 82: $34-55$.

6. Lancaster, K. J., 1966. A New Approach to Consumer Theory. J .Political Economy,74:132157.

7. McMillan, M. L., Reid B. G. and D. W. Gillen, 1980. An Extension of the Hedonic Approach for Estimating the Value of Quiet. Land Economics, 56: $315-328$. 
8. Calhoun, C. A., 2001. Property Valuation Methods and Data in The United States. Housing Finance International, 16: 12 - 23.

9. Brorsen, B. W., Grant W. R. and M. E. Rister, 1984. A Hedonic Price Model for Rough Rice Bid/Acceptance Markets. American J. Agri. Econ., 66: 156 - 163.

10. Ethridge, D. E. and B. Davis, 1982. Hedonic Price Estimation for Commodities: An Application to Cotton. Western J. Agri. Econ., 7: 293 - 300.

11. Wilson, W. W., 1984. Hedonic Prices in the Malting Barley Market. Western J. Agri. Econ., 9: $29-40$.

12. Blomquist, G. and L. Worley, 1981. Hedonic Prices, Demand for Urban Housing Amenities and Benefit Estimates. J. Urban Econ., 9: 212 - 221.

13. Witte, A. D., H. J. Sumka and H. Erekson, 1979. An Estimate of a Structural Hedonic Price Model of the Housing Market: An Application of Rosen's Theory of Implicit Markets. Econometrica, 47: $1151-1173$.

14. Milon, J. W., Jonathan G. and D. Mulkey, 1984. Hedonic Amenity Valuation and Functional Form Specification. Land Economics, 60:378- 387.

15. Pope, C. A. and J. R. Stoll, 1985. The Market Value of Ingress Rights for White-Tailed Deer Hunting in Texas. Southern J. Agri. Econ., 17: 177 -182 .

16. Livengood, K. R., 1983. Value of Big Game from Markets for Hunting Leases: The Hedonic Approach. Land Economics, 59: 287-291.

17. Pope, C. A., Adams C. E. and J. K. Thomas, 1984. The Recreational and Aesthetic Value of Wildlife in Texas. J. Leisure Res., 16: 51 - 60.

18. Messonnier, M. L. and E. J. Luzar, 1990. A Hedonic Analysis of Private Hunting Land Attributes Using an Alternative Functional Form. Southern J. Agri. Econ., 232: 129 - 135.

19. Freeman, M. A., 1979. The Benefits of Environmental Improvement. Washington, D.C.: Resources for the Future.

20. Harrison, D. and D. L. Rubinfeld, 1978. Hedonic Housing Prices and the Demand for Clean Air. J. Environ. Econ. Management, 5: 81 - 102.

21. Frew, J. and B. Wilson, 2000. Estimation The Connection Between Location and Property Value, Essay in Honor of James A. Graaskamp, Boston, MA: Kluwer Academic Publishers.

22. Fletcher, M., Gallimore P. and J. Mangan, 2000. The Modeling of Housing Sub-markets. J. Property Investment \& Finance, 18(4).

23. Mieszkowski, P. and A. M. Saper, 1978. An Estimate of the Effects of Airport Noise on Property Values. J. Urban Econ., 5: 425 - 440.
24. Damm, D., Lerman S. R., Lemer-Lam E. and J. Young, 1980. The Response of Urban Real Estate Values in Anticipation of The Washington Metro. J. Transport Econ. Policy, September, 315 - 336.

25. Uyeno, D., Hamilton S. W. and A. J. G. Biggs, 1993. The Density of Residential Land Use and The Impact of Airport Noise. J. Transport Economics and Policy, January, XXVII(1).

26. Ridker, R. and J. Henning, 1982. The Determinants of Residential Property Values with Special Reference to Air Pollution. Rev. Econ. Stat., 46: $246-257$.

27. Graves, P., Murdoch J. C., Thayer M.A. and D. Waldman, 1988. The Robustness of Hedonic Price Estimation - Urban Air Quality. Land Economics, 64: $220-233$.

28. Lenk, M. M., Worzala E. M. and A. Silva, 1997. High-tech Valuation: Should Artificial Neural Networks Bypass The Human Valuer? J. Property Valuation \& Investment, 15: 8- 26.

29. Owen, C. and J. Howard, 1998. Estimation Realisation Price (ERP) by Neural Networks: Forecasting Commercial Property Values. J. Property Valuation \& Investment, 16: 71 - 86.

30. Tay, D. P. H. and D. K. H. Ho, 1991. Artificial Intelligence and The Mass Appraisal of Residential Apartments. J. Property Valuation \& Investment, 10: $525-539$.

31. Do, A. Q. and G. Grudnitski, 1992. A Neural Network Approach to Residential Property Appraisal. The Real Estate Appraiser, 58: 38 - 45.

32. McCluskey, W., 1996, "Predictive Accuracy of Machine Learning Models for The Mass Appraisal of Residential Property. New Zealand Valuers' J., July: $41-47$.

33. Worzala, E., Lenk M. and A. Silva, 1995. An Exploration of Neural Networks and Its Application to Real Estate Valuation. The J. Real Estate Res., 10: 185 - 201.

34. Stanley, M., Alastair A., Dylan M. and D. Patterson, 1998. Neural Networks: The Prediction of Residential Values. J. Property Valuation \& Investment, 16: $57-70$.

35. James, R. C. and E. B. Carol, 2000. Artificial Neural Networks in Accounting and Finance: Modeling Issues, Int. J. Intelligent Systems in Accounting. Finance \& Management, 9: 119-44.

36. Mester, L. J., 1997. What's The Point of Credit Scoring?, Business Review, Federal Reserve Bank of Philadelphia, Sep./Oct. 1997: 3 - 16.

37. Freeman, M. A., 1993. The Measurement of Environmental and Resource Values, Washington, D.C. Resources for the Future. 
38. Cooper, M. L., Deck L. B. and K. E. McConnell, 1987. On the Choice of Functional Form for Hedonic Price Functions, Resources for the Future Discussion Paper QE87-08, Washington, DC. Resources for the Future.

39. Shonkwiler, J. S. and J. E. Reynolds, 1986. A Note on The Use of Hedonic Price Models in The Analysis of Land Prices at The Urban Fringe. Land Economics, 62 (1).
40. White, H., 1982. Maximum Likelihood Estimation of Misspecified Models. Econometrica, 50: 1 - 26.

41. Gujarati, D. N., 1995.Basic Econometrics (3rd ed). McGraw-Hill.

42. Maddala, G. S., 2001. Introduction to Econometrics (3rd ed). John Wiley \& Sons.

43. Ward System Group Inc., 1993. NeuroShell 2, release 4.0. 